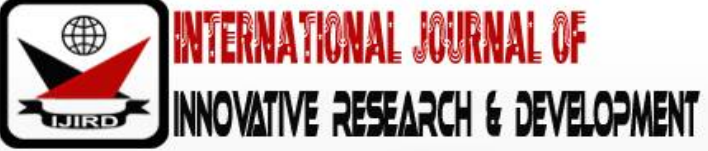

ISSN 2278 - 0211 (Online)

\section{Human and Public Relations in Managing Education in Kenya}

\author{
John Njenga Kimemia \\ Associate Professor, Educational Communication and Technology, \\ Kenyatta University, Nairobi, Kenya
}

\begin{abstract}
:
The human dimension in management has been underscored by many authorities including the Human Relations School of thought (as advocated by people such as Fayol, Mayo, Douglas Mcgregor, etc.). Among the crucial resources identified for effective management the primary one is Human Resource. The others such as equipments, physical facilities, funds (money) as well as 'time' are secondary to the human factor. The scientific management approach identified its principles based on concepts such as planning, organizing, directing, coordinating and division of labour, specializing and evaluation. The humanistic management approach identified the principles of human relations, decision- making, delegation, communication and problem solving. The Human and Public Relations as a mediator of the two schools of the thought in management emphasizes the importance of the human person, moral and social relationships as well as organizational (contractual) obligations that are displayed in authority and responsibility of each member of the organization. The paper highlights the centrality of the human factor in management. It attempts to bring together the two classical schools of thought focusing on the human (individual) needs, roles and expectations which must be met or satisfied so that the human resource can meet the organizational functions, needs and expectations that are explicitly or implicitly identified as the organizational goals and objectives to be achieved.
\end{abstract}

Keywords: Human relations, public relations, human resource, human factor, personnel management, humanizing productivity and profitability, people, ten commandments of human and public relations

\section{Introduction}

There are three schools of thought which have involved psychologists at different epochs. The first school of thought comprised psychologists who viewed man as instinctive, irrational and doomed to conflicts. A second school of thought comprised behaviourists (psychologists) who view man as a puppet, controlled by the web of his environment. Yet a third school of thought in the recent past (sixties - eighties) views man as a consolidated being who is growing, generous, healthy being who is in control of his/ her destiny. The basic elements in human behaviour is well articulated by the domain theory with notions of identity (ID), Ego and Superego. These elements are represented through hunger, thirst, nakedness, peace, love, psychological and social ethics the sense of belonging etc. An overview of the three schools of thought indicates the evolution of organizational behaviours which are depicted as;

- Task oriented approaches

- Human oriented approaches and.

- Situational oriented approaches, highlighting on motivating people to perform expected tasks within specified period of time.

\subsection{Definition and the Concept of Human and Public Relations.}

Human and public relations is an approach to organizational theory which emphasizes on the importance of organizations effectiveness in order to underscore the importance of human and public relations two common adages state that:

- The human being is the centre and yardstick of everything (cf: Demello E.)

- If you dig very deeply into any problem, you get people; (cf: Wislon Watson) The Human element is uniquely important in management because the human resource is the most crucial resource in any organization for the effective production and utilization of goods and services. Other resources such as facilities, equipments money or time are secondary to the human factor. The concept of management has the human element at the centre. The management process from the humanistic approach involves aspects such as human relations, communication, delegation, decision - making and problem solving. 
Human and public relations may thus be defined as;

- The art of accomplishing predetermined organizational goals

- A process that promotes individual efficiency and satisfaction

- A process that promotes group solidarity and effectiveness

- A process that assists the organizations productivity profitability and growth

- A process that harmonizes the needs and expectations of the organization as well as the needs and expectations of the individual on the other hand.

An organization with good human relations set up will allow the growth of persons in it their participation and their welfare as individuals and groups. Human and public relations is currently referred to as Organizational behaviour. The main consideration for the human element in organizations gained prominence with Industrial revolution. Mass productivity in industry gave rise to surplus goods and increased knowledge leading to increased wages for workers, shorter working hours and job satisfaction. For example, in 1800 a welsh industrialist (Robert Owen) cared for human needs of his employees and became the Father of personnel management. In 1911, Fredrick Taylor developed the concept of scientific management resulting in improved recognition and productivity for individual workers. Taylor argued that' there were best men for a job just as there were best machines for a given job. Although Taylor was associated with advancement of the 'man - machine' theory or the 'input - output' concepts he is rightly viewed as the Father of scientific management

The concern for workers welfare in organizations has evolved gradually over the years giving rise to National Personnel Associations, such as our Central Organisation of Trade Unions (COTU) Kenya National Union of Teachers (KNUT) and the Federation of Kenya Employers (FKE). In the 1920s, scholars such Elton Mayo (Harvard University) researched into the Human element in commerce and Industry. The findings from these studies transformed the earlier school of thought as advocated by the likes of Fredrick Taylor to the second school of thought where organizations were viewed as social systems with workers as vital components i.e. the human relations school of thought. The emphasis focused on 'humanizing' productivity and profitability in organizations. These developments in human resource management gave rise to organizational behaviour characterized by:

- $\quad$ Attempts to overcome cultural barriers and trying to understand the human factor in organizations in dealing with the changes in science, technology, productivity and profitability.

- $\quad$ Top management (managers) focusing on acquiring knowledge, skills and attitudes relevant to handling human elements in organizations.

- $\quad$ Social concerns and human welfare giving rise to labour movements, compensation schemes, trade unions and professional associations to cater for human factors such as improved conditions and terms of service, improved remunerations and generally improved positive attitudes towards 'people' in organisations. The social responsibility of organizations towards people have improved tremendously. For instance, the Webuye paper mills has a responsibility to care for its workers as well as the communities around who are affected by the industrial waste from the mill entering into River Nzoia.

- Increasing complexity of the working environment requires more attention from the management. As an organization increases in size and the technologies advance, more employees become less aware of the products and services they produce and how these product and services may affect their social welfare. These factors have necessitated consideration of theories and practices in motivation as have been advocated by such management gurus as Douglas McGregor (1957) expounding on specific assumptions such as the Theory X and Theory Y. Therefore, organizational behaviourists have focused on the nature of people as individuals, and groups in respect to personalities specialization or professionalism. In particular, concern in the value of a person, i.e. human dignity has been related and compared to the organization or the dignity of labour. The nature of organizations has been related to social systems and mutual human interests. The nature of people and organizations has led to industrial harmony through individual performance and tangible organizational results.

\section{Human Relations Assumptions}

There are seven operational assumptions on effective measures to improve and promote successful human relations: These are

- Good human relations practice is the product of experience, intuition and interdisciplinary generalization that an individual take.

- $\quad$ An employee participation is often essential to higher productivity and greater human satisfaction

- $\quad$ The role assumptions stem from the variety of demands and individual's job oriented - role and the informal group - oriented role.

- Teamwork is an indispensable element of organizational survival Teamwork is a matter of mutual anticipation and agreement on goals.

- Human being is diversely motivated and has a hierarchy of needs which are quite changeable. (cf; Abraham Maslow:1943)

- An organization is a social system. The work situation should be viewed as a network of interrelated elements and a major feature of modern human relations. 
- We can develop skills in human relations. We may be trained to be aware, sensitive and competent to cope with human problems in organizations.

\section{Human Relations at Workplace and Its Relationships between People and Organizations (Authority, Responsibility and Influence)}

The concept of authority is simply defined as the right to command. According to human relations theorists such as 'Henry Fayol' Authority is the right to give orders and the power to exert obedience.

Authority may delegate to subordinates so that they are able to make decisions and to implement these decisions in their respective operations. However, it is important to remember that delegation of authority to subordinates does not absolve the responsibility of superiors for the actions and outcomes of their decisions. The superiors remain accountable and responsible for the actions of their subordinates.

Responsibility is the duty to perform the assigned tasks in a satisfactory manner. It is the obligation to perform certain activities that are assigned to the individual. The source of responsibility lies within the individual. If one accepts a job then that individual should ensure the job is completed to the best of his/ her ability. Responsibility is governed or controlled by two aspects of obligations. These are the contractual obligation and moral obligation. An employee has contractual obligation to ensure that the job assigned is done and also has moral obligation to ensure that the job is done honestly and efficiently. Since responsibility as an obligation that one accepts, it cannot be delegated to the subordinates even when the activity is performed by the subordinates. Responsibility is the accountability for the authority vested in the individual or office. Authority must be used in a responsible manner. The available literature identifies different types of 'authority' which may be exercised by an individual or the relevant office either directly or indirectly. These types of authority may comprise the following (i)

Formal/ structural or legal authority (ii) Expert or professional authority (iii) Traditional or inherent authority (iv) Charismatic authority (v) Moral (vi) Physical (vii) Parental and (viii) clerical authority.

The legal/ formal authority is based on rank or position of the person in the organizational structure. It may also be called official authority i.e. authority that is vested in a respective office. This type of authority could be provided either by law or social rules. For example, the authority of a policeman to arrest a criminal or the authority of a company director to hire and fire an employee. The expert or professional authority or simply the 'sapiential authority is based on knowledge, skills and experience of the individual. For example, the authority of a doctor to prescribe medicine and the authority of a mechanic to repair the client's vehicle.

Traditional authority evolves from social order and the community. This authority is passed from father to son e.g. from the king to the prince. The traditional chief and the father in a family enjoy traditional authority.

The charismatic authority is based on the personality and natural power of leadership of the individual. For example, a leader commands respect of his/her followers because of his/ her personality and integrity. These leaders include politicians and religious leaders. Usually, a charismatic leader is a forceful speaker or orator. For example, the late Mzee Jomo Kenyatta and the late Ayattolah Khomeni and the late John F. Kennedy.

The moral authority is based on the integrity and 'goodness' of the individual. The physical authority is based on physical superiority of the individual. The statutory authority is based on the legal powers e.g. the authority of a factory inspector, it is also known as the structural or formal authority. The parental authority is based on the special relationship which exists between parents and their children. The clerical authority is often associated with the charismatic authority. However, this type of authority is sometimes called reverence authority. It is the relationship

that exists between the 'men of the cloth' and the laymen. Church ministers, priests, rabbis and chaplains fall in this category.

\section{People as the Focal Point in Human and Public Relations}

In the introduction, we stated that 'If you dig deeply into any problem, you get people'. The implication in this adage is that the relationships within and between people inside and outside organizations are extremely crucial in determining their productivity, delivery of goods and services as well as success or failure. When dealing with 'people' the following points should be considered.

- It is probable that your reputation has preceded you in terms of either winning their confidence and respect or loosing that respect and confidence resulting in non - acceptance.

- Whenever one is dealing with people it is important to remember that one's appearance, manners, personality, knowledge and even dressing will be under scrutiny and will contribute in forming other people's opinion about him/ her.

- One's future conduct will be compared against the first impression to allow consolidated opinion to be formed.

- There is a tendency for 'black marks' to be awarded after the first impressions were positive.

- There are always allies and critics in an organization and their feelings will normally be attributed to the individual and his/ her actions.

The relationships at workplace will be labelled or categorized into:

- Seniors (seniors vs juniors)

- Subordinates (bosses vs subordinates)

- Colleagues (partnerships)

- Specialists vs non-specialists

- Shop-stewards or union representatives 
- Officials

- Customers

- Visitors/ Guests.

\section{Action Reactions Cause and Effects}

Generally, actions and reactions may be planned, foreseen, calculated and measured. It is not so with people and human relations. For example, a simple action or remark can produce a reaction sometimes completely unexpected in its nature, impact and severity. For instance, suppose a smoker asks to give Otieno / Atieno a hand?" what would you do? The latter is normally seen and the former is invisible.

Opinions, feelings and emotions are personal and sometimes private. They are formed and arise in the mind, invisible to the world. All that the observant onlooker can do is look for attitudes and physical signs such as facial expressions to try and determine why a person is reacting in a particular way. Normally, you may ask a person why he/ she has reacted so, by the reply, if you get one, may be far from the truth. A skilled interviewer observes as closely as he listens.

\section{The Individual}

No two people are exactly alike. The individual is a complex combination of many factors and in our dealings with people it is important that we try to understand their makeup or what is popularly called 'chemistry'. There are many causes for unexpected reaction. If one understands the person in question, then one is in a better position to predict the reaction and the effect it may have on the two. An individual may react to situations or comments due to any of these factors or a combination of them.

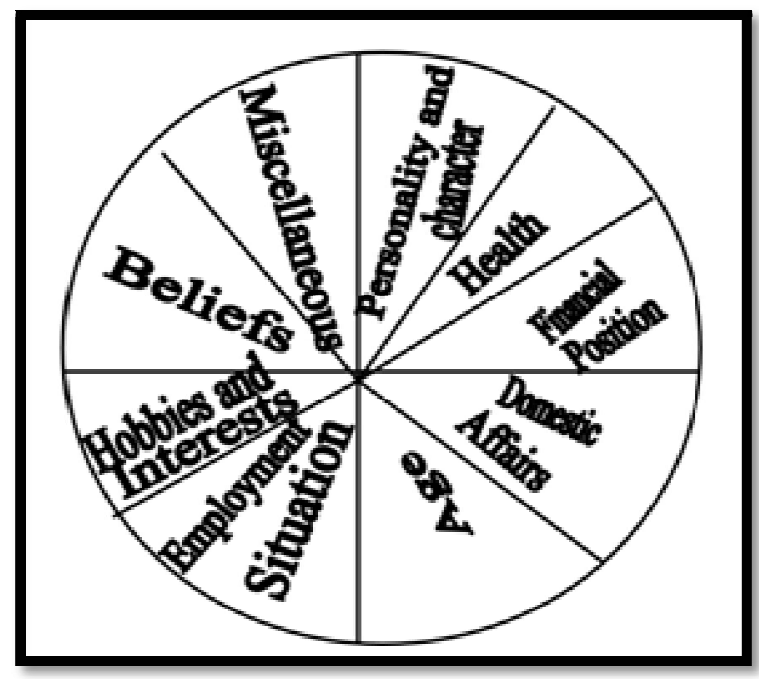

Figure 1

\section{1. Determinants of Individual's Cause and Effect Reactions}

NB. Few of these factors remain static, thus it is essential that one does not become habitual when dealing with an individual.

\section{Hints for Good Human Relations}

Treat people as individuals. For example, 'a pat on the back' at the right time can work wonders for morale and assists in gaining future co-operation and effort. It can also pave the way for criticism being accepted without ill - feeling and resentment.

Remember your manners at all times. This refers to common statements such as 'say what you mean and mean what you say'. You must communicate to maintain good relationships.

Be tactful: Do nothing to hurt your team or others. Let the other person save his/ her face. Don't nag and don't show impatience at the rate of progress. Don't pass the buck.

- Admit your mistakes and the team's mistakes; they are your mistakes too. As the leader, accept more than your fair share of the blame. Depersonalize comments and criticism - think about the idea not about the person.

- Keep your temper - Losing you temper always hurts the other person and will damage your relationship.

- Be patient - Keep your emotions and those of your team, cool and calm.

- Be tolerant - Mistakes will happen - be tolerant of them even while trying to avoid their being repeated. Accept your team as they are. It is your job to improve their work and their attitudes, but accept that this will be a gradual process.

- Be courteous - Treat your team with courtesy and respect. They will respond in kind and also work better. NB. They say 'courtesy costs nothing' Show that you are always willing to do that little bit extra - for the job and for them.

- Do as you would be done by others - Treat your team in the way you would like your superiors to treat you. 
Acknowledge importance (worth whileness) Treat your team as individuals. Remember personal details. Listen to their ideas and encourage suggestions.

\section{Effects of Relations on Performance and Productivity}

Remember: Being considerate always makes the leader's job easier because it improves group atmosphere. The following points will improve the leader's relationships with his employees or subordinates thus leading to better performance and increased productivity.

Communicate - See and talk to your employees/ subordinates regularly. Make them aware of your own positive attitudes towards them and their work. Let them get to know you as a person. NB. Communication is a two- way processes. It involves receiving as well as giving. Get your team to talk to you and listen to them as people.

Praise - Always give praise where it is due, but avoid flattery. Always express approval, appreciation, commendation and thanks. What do people give and never borrows? Answer - Thanks.

Be sincere - As said earlier 'mean what you say and say what you mean' Don't make rush promises you have no intention of keeping. Keep the promises you make.

Be loyal- To each member of the team - Do not criticize one member in front of the others. Or even behind his/ her back. Defend individuals when necessary.

To your team or group - be objective and reasonable but don't criticize your team in front of others. Fight for your team when you have to. To the company (organization).Don't criticize the company's

(organization's) policy to your team. If you snipe at top management behind their back, your team will suspect you do the same to them. Believe in your team and its capabilities-it is through them you have to work.

5.Be enthusiastic - Your enthusiasm will rub - off on your team and inspire them. Remember; the leader must aim to generate of cultivate the following virtues in his team and within the organization.

- $\quad$ Respect

- Trust

- Loyalty And

- Co - Operation.

9.1. Handling Human and Public Relations Problems

In dealing and handling human and public relations problems the manager/ boss should consider the following points;

- Recognizing that individuals are different.

- Gather all information on a continuous basis.

- For similar needs, two individuals may require different approaches in solving them.

- All information about individuals must remain confidential.

- Allow time for gathering information in your daily routine activities.

- Results are not necessarily immediate or even apparent

- Take immediate action whenever possible.

- Eliminate or change the cause.

- Keep informal notes on each case.

- Know each individual so that rapport is established.

- Separate facts from opinions

- Do not forget that you are involved and that you may have to change

- Do not let suggestions for change appear to come from the individual.

- Recognize that in some situations action by you is not appropriate.

- Do not express surprise.

- Do not express moral judgements, be objective.

- Find out what the individual wants.

- Needs may be changed by changing conditions.

- Ask for assistance from your colleagues or other managers.

9.2. Guidelines for Good Human and Public Relations Practice

An effective manager or leader must take into account the following points that either concern himself as a person or concern his employees or subordinates.

- Understand and accept people as they are.

- Be aware and sensitive to other's points of view along with an ability to maintain your own position.

- Be willing to understand and to respond to the feelings and attitudes of others which might not be purely logical from your own frame of reference.

- Be aware of yourself and appreciate the scope of your influence on others.

- Appreciate the social structure or social system in which you are involved.

- Be realistic about your authority and status and aware of how they affect others.

- Attempt to predict how the organization will respond to change that you introduce.

- Make use of your experience and abstract generalizations about the social environment while taking any action. 
9.3. The Ten Commandments of Humans and Public Relations.

- Give facts; inform in advance.

- Do not dominate allow self-respect.

- Promote competitive spirit among people but avoid a fight.

- Set examples for others e.g. respect to their superiors and their colleagues

- Consider others' sentiments and social situations, it is out of these that their World is built and they view the World through these social mirrors.

- Make others feel important - appeal to their drives. Give them opportunities not only for advancement but also for expression. Provide them with reasonable security, safe and healthy working conditions.

- Be firm. Do not give concessions too easily. Let those others feel they have earned them fairly.

- Treat each person as an individual, determine what makes him/ her valuable.

- Make decisions as fairly as possible after considering the valuable facts.

- Be especially careful to be objective in making decisions.

\section{Conclusion}

An effective personnel manager or human Resources manager should have blends or combinations of the three managerial styles, taking cognizance of the human and public relations discussed in this paper. These three major managerial styles or approaches are (i) Job - centred or task-oriented manager (ii) People centered or human resource manager and (iii) Situational or on - the spot manager. The three managerial styles depict a good human and public relations manager who is aware and practices the following virtues:

- People need to be treated with respect and dignity

- People are aware of their rights and they need to be free from threats and coercion.

- People will resist any attempts that tries to threaten or coerce them in the organization.

- People's attitudes, skills and culture will inhibit or promote human relations.

- People are able to distinguish between sincerity and pretences. What they want sincerity and honesty.

- The manager or generally any leader should develop an atmosphere of trust and confidence from others i.e. his/ her colleagues and subordinates.

- People are concerned by the behaviour of the leader (manager) and thus he/ she should encourage them by good deeds.

- As mentioned earlier a leader or manager should admit and learn from past mistakes.

- The leader (manager) should avoid passing the back of blames to others.

- The manager or leader should try to understand others as well as making others understand him/ her.

- Overall the manager or leader should create favourable conditions or environment necessary for human and public relations. This is the central or focal point in any effective style of management including human resource management. As mentioned in the introduction 'if we go in depth into any problem, we will find people'. Similarly, if we take care of human and public relations aspects then we shall have succeeded in managing all other resources.

This is what is summarized as the centrality of factor human factor in any management style as well as the emphasis that human and public relation are the pinpoint in any management.

\subsection{Group Discussion and Exercises for Human and Public Relations}

NB. Small groups could discuss these aspects and report back to the plenary session,

Consider the merits and demerits of communicating using the following methods or strategies.

- Pinning messages on the Notice Boards.

- Writing minutes/ letters to individuals to give them warnings, instructions and general information.

- Calling staff meetings to discuss issues related to individual staff performance.

- d.) Face to face consultations with individual employees or members of staff in the managers' office.

- c) Informal consultations with individual colleagues, superiors and subordinates over a cup of tea or coffee.

Mr. Mpole has just been appointed H.o.D at Kenya Technical College for the first time. He has been working in the field as a Factory Supervisor and then a Production Engineer. (a) What problems in human and public relations do you think Mr. Mpole is likely to encounter with his colleagues, subordinates and superiors in his new position? (b) What advice would you give him if you are his (i) Boss (ii) Colleague or (iii) Junior.

\section{References}

i. Blake et al (1975) Group and organizational Team Building in 'Theories of Group Processes' London. Wiley pub.

ii. Cutlip and Centre (1985) Effective Public Relations Prentice Hall.

iii. Keith Davis (1987) Human Behaviour at work. Organizational Behaviour U.S.A.

iv. McGraw Hill Inc.

v. Nedler et al (1979) Managing Organizational Behaviour. Toronto. Little Brown \& Co.

vi. Newson and Scott (1985) This is PR: The Realities of Public Relations. Wadworth Pub Co. California.

vii. Nolte L.W (1979) Fundamentals of Public Relations Pergamon Pub. 
viii. Stewart R, (1979) The Reality of Management London. Heinemann Ltd.

ix. Republic of Kenya (1986) Economic Management for Renewed Growth. Sessional

x. Paper No. 1 Nairobi. Government Printer.S 